\title{
A Thermally Stable Protein EPP1 of Corn Borer Ostrinia furnacalis Regulates Hemocytic Encapsulation
}

\author{
Jian $\mathrm{Hu}^{\mathrm{a}, \mathrm{b}}$ Xiangping Feng ${ }^{\mathrm{b}}$ Li Yao $^{\mathrm{b}}$ Meng Meng ${ }^{\mathrm{b}}$ Yan Du $^{\mathrm{b}}$ Yipei Dong \\ Zhenkun Song $^{b}$ Mengli Tian $^{b}$ Yu Chen ${ }^{b}$ \\ aSchool of Agriculture, Sun Yat-Sen University, Guangzhou, China; bState key Laboratory of Biocontrol, School of life \\ sciences, Sun Yat-Sen University, Guangzhou, China
}

\section{Keywords}

Encapsulation-promoting protein · Hemocytes - Plasma .

Aggregation · Insect cellular immunity

\begin{abstract}
Encapsulation is a vital cellular immune reaction of host insects against endoparasitoids; however, how encapsulation is regulated is still unclear. Utilizing a cell line, SYSU-OfHem $\mathrm{C}$, derived from larval hemocytes of the Asian corn borer Ostrinia furnacalis to assay for encapsulation response, an encapsulation-promoting protein (OfEPP1) was isolated from the plasma of $O$. furnacalis larvae. OfEPP1 is a novel secretory protein, which exists only in O. furnacalis to date. The OfEpp 1 gene is intronless and encodes a protein containing several groups of short repetitive sequences and a high proportion of proline residues (18.3\%). OfEPP1 is a thermally stable protein that is mainly expressed in fat bodies, and its accumulation could be induced by the injection of foreign objects (Sephadex beads). Eukaryotically expressed recombinant OfEPP1 promoted hemocytes to encapsulate Sephadex beads, while prokaryotically expressed protein did not, indicating that posttranscriptional modification affects the function of OfEPP1. The encapsulation-promoting function of OfEPP1 could be neutralized by the addition of polyclonal antibodies against OfEPP1 or disrupted by the injection of
\end{abstract}

karger@karger.com www.karger.com/jin

Karger"

GOPEN ACCESS
(C) 2021 The Author(s)

Published by S. Karger AG, Basel

This is an Open Access article licensed under the Creative Commons Attribution-NonCommercial-4.0 International License (CC BY-NC) (http://www.karger.com/Services/OpenAccessLicense), applicable to the online version of the article only. Usage and distribution for commercial purposes requires written permission.
dsRNA targeting OfEpp 1. Eukaryotically expressed OfEPP1 promoted the aggregation, but not spreading, of both granulocytes and plasmatocytes. Immunocytochemistry analysis showed that eukaryotically expressed OfEPP 1 could bind to the surface of hemocytes. Therefore, we speculate that OfEPP1 possibly promotes hemocytic encapsulation by binding to the surface of hemocytes as a ligand to induce their aggregation. This study provides evidence clarifying the mechanism of encapsulation in insects.

(C) 2021 The Author(s)

Published by S. Karger AG, Basel

\section{Introduction}

Encapsulation is a vital cellular immune reaction in insects to defend against foreign objects that are too large to be cleared by phagocytosis, such as the eggs of endoparasitoids or nematodes [1], which are important biological pest control agents. Therefore, knowledge about the mechanisms of encapsulation will be beneficial to the utilization of parasitoids in pest control. Encapsulation refers to the formation of an overlapping sheath of immune hemocytes around a target object [2], and it is mod-

Jian Hu and Xiangping Feng contributed equally to this work.
Correspondence to:

Jian Hu, lsshj@mail.sysu.edu.cn 
ulated by plasma factors. Immune hemocytes, including granulocytes and plasmatocytes, function in different ways in different lepidopteran insects during encapsulation. For example, in Pseudoplusia includens, granulocytes participate in the initiation and termination of encapsulation and plasmatocytes form the main body of capsules [3], whereas in Manduca sexta, plasmatocytes but not granulocytes bind to foreign objects, and both plasmatocytes and granulocytes construct the main body of the capsule [4]. Plasma factors in insect hemolymph play various regulatory functions during this process.

Some peptides function in regulating hemocyte adhesion to promote encapsulation. Encapsulation-promoting factor was the first identified peptide to function by mediating hemocyte adhesion in Heliothis virescens [5]. The function of plasmatocyte-spreading peptide (PSP) in promoting hemocytic spreading has been well studied $[6$, 7]. Several specific residues of PSP have been shown to bind to its receptor on hemocytes to maintain PSP's biological activity [8-10]. Growth-blocking peptide (GBP), a homolog of PSP, was also found to promote the adherence of plasmatocytes to the surface of foreign objects [11, 12]. GBP-binding protein, which is expressed in oenocytoids, can clear GBPs in insect hemolymph [13] and thus suppress hemocytic spreading and encapsulation [14]. Furthermore, several immulectins (IMLs) have been shown to participate in encapsulation in lepidopteran insects, such as IML- 1 and 2 in $M$. sexta $[15,16]$, encapsulation-promoting lectins in $M$. separata [17], a C-type lectin in the cotton bollworm Helicoverpa armigera [18], and IML-10 in Ostrinia furnacalis [19]. IMLs are members of the C-type lectin superfamily with 2 carbohydrate recognition domains. Some of these IMLs bind directly to hemocytes and promote encapsulation $[15,19,20]$. C-type lectins DL2 and DL3 in Drosophila melanogaster mediate hemocytic encapsulation and melanization too [21]. In addition, a few non-lectin proteins also participate in encapsulation. Two early-stage encapsulation-related proteins [22] and an $86-\mathrm{kDa}$ protein homologous to insect diapause [23] were identified in Tenebrio molitor. Apoli-

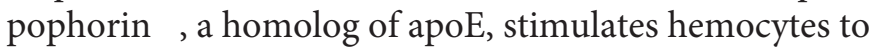
form capsules on non-self particles in Galleria mellonella [24]. A $7.7-\mathrm{kDa}$ protein homologous to juvenile hormone-inducible protein secreted by hemocytes was shown to be involved in hemocytic encapsulation in $H$. armigera [25]. Eicosanoids were also shown to be involved in encapsulation in D. melanogaster parasitized by the endoparasitoid wasp Leptopilina boulardi [26, 27].

Despite progress in identifying encapsulation-related factors, how these factors induce hemocytes to recognize foreign objects closely related to host insects and encapsulate them is still poorly understood. Therefore, more factors related to encapsulation should be identified and studied. Due to the small size of insects, it is hard to collect enough hemolymph to isolate factors related to encapsulation directly. Furthermore, individual differences and the effect of residual plasma on hemocytes also make it difficult to identify encapsulation-related factors. Continuous hemocyte cell lines should be helpful in overcoming these problems. Hemocyte cell lines have been established for the lepidopteran insects Helicoverpa zea [28], Mamestra brassicae [29], Spodoptera exigua [30], and Ostrinia nubilalis [31]. In addition, a cell line, SYSU-OfHe$\mathrm{C}$, originating from larval hemocytes of $O$. furnacalis was established in our laboratory [32]. After being cultured for dozens of passages in medium without larval plasma, the SYSU-OfHe-C cell line did not show immune behaviors; however, encapsulation ability could be activated by addition of larval plasma [32]. Therefore, this cell line provides a convenient method to identify factors related to encapsulation in insect plasma.

O. furnacalis (Lepidoptera: Pyralidae), a worldwide agricultural pest that destroys corn and some other crops, causes more than 9 million tons in corn yield losses per year [33]. Macrocentrus cingulum is the predominant parasitoid of $O$. furnacalis, and it may parasitize up to $70 \%$ of corn borers in the field. In this study, a thermally stable protein, OfEPP1, which may regulate hemocytic encapsulation by promoting the aggregation of hemocytes, was isolated from the plasma of $O$. furnacalis larvae using the cell line SYSU-OfHe-C. This study lays a good foundation for clarifying the mechanism of encapsulation in Lepidoptera. The findings will also aid future efforts to elucidate the immune evasion strategies of parasitoids.

\section{Materials and Methods}

Insects and Cell Line

Insects used in this research were originally collected from cornfields in Jiangsu Province, China, and reared continuously in our laboratory. Larvae were reared, as described previously [34]. The SYSU-OfHe-C cell line was also maintained, as described previously [32].

Protein Identification, Separation, and Purification

O. furnacalis larvae on the second to third day in the fifth instar were sterilized and bled. Eight milliliters of collected hemolymph containing a little of phenylthiourea, which was used to inhibit melanization, was centrifuged at $4,000 \times g$ for $5 \mathrm{~min}$ at $4^{\circ} \mathrm{C}$. The plasma was then collected and boiled at $100^{\circ} \mathrm{C}$ for $5 \mathrm{~min}$ and cen- 
trifuged at $10,000 \times g$ for $5 \mathrm{~min}$ at $4^{\circ} \mathrm{C}$ to remove the heat-denatured proteins. Plasma without heat-denatured protein was analyzed with Sephadex A-25 beads, as described in the section Encapsulation Analysis to confirm its encapsulation-promoting ability and then resolved on a reverse-phase (RP) $\mathrm{C}_{18}$ HPLC column (Zorbax $300 \mathrm{SB}, 4.6 \mathrm{~mm} \times 150 \mathrm{~mm}, 5 \mu \mathrm{m}$. Agilent, CA, USA) using a $5-80 \%$ gradient of $\mathrm{CH}_{3} \mathrm{CN}$ (5-30\%, $40 \mathrm{~min} ; 30-60 \%, 15 \mathrm{~min} ; 60-80 \%, 15$ $\mathrm{min} ; 80 \%, 10 \mathrm{~min}$ ) in $0.1 \% \mathrm{CF}_{3} \mathrm{COOH} / \mathrm{H}_{2} \mathrm{O}$ at a flow rate of 0.5 $\mathrm{mL} / \mathrm{min}$. Fractions with absorbance greater than 200 were collected and concentrated separately using a Speed Vacuum Concentrator (RVC 2-18, Christ, Osterode am Harz, Germany) to remove $\mathrm{CH}_{3} \mathrm{CN}$ and $\mathrm{H}_{2} \mathrm{O}$. After encapsulation analysis, performed, as described above, the active fraction was further separated using 2 different methods. One portion of the active fraction was resolved on the same $\mathrm{RP}_{18}$ HPLC column again using a 30-80\% gradient of $\mathrm{CH}_{3} \mathrm{CN}(30-50 \%, 50 \mathrm{~min} ; 50-80 \%, 10 \mathrm{~min})$ in $0.1 \% \mathrm{CF}_{3} \mathrm{COOH} /$ $\mathrm{H}_{2} \mathrm{O}$ at a flow rate of $0.5 \mathrm{~mL} / \mathrm{min}$. Another portion of the active fraction was separated on a gel filtration column (Superose 12 10/300 GL, GE) using PBS ( $\mathrm{pH} \mathrm{7.4)} \mathrm{at} \mathrm{a} \mathrm{flow} \mathrm{rate} \mathrm{of} 0.5 \mathrm{~mL} / \mathrm{min}$. After encapsulation analysis, again performed, as described above, the active fractions $(20 \mu \mathrm{g})$ were separated by $12 \%$ SDS-PAGE (110 $\mathrm{V}, 1 \mathrm{~h}$ ) with the Mini-Protean Tetra Electrophoresis System (BioRad, Hercules, CA, USA) for further MS analysis.

\section{MS Analysis}

MALDI-TOF MS analysis was performed using an Ultraflex III MALDI TOF/TOF (Bruker, Daltonics, Germany) to obtain the peptide mass fingerprinting and MS-MS data. Protein bands in an SDS-PAGE gel stained with Coomassie Brilliant Blue were cut out, decolored with $50 \mathrm{mM} \mathrm{NH}{ }_{4} \mathrm{HCO}_{3} / \mathrm{CH}_{3} \mathrm{CN}$ (1:1) for $20 \mathrm{~min}$ at $37^{\circ} \mathrm{C}$, dried by vacuum for $10 \mathrm{~min}$, reduced by incubating in fresh $10 \mathrm{~mm}$ DTT in $25 \mathrm{mM} \mathrm{NH}_{4} \mathrm{HCO}_{3}$ at $56^{\circ} \mathrm{C}$ for $1 \mathrm{~h}$, alkylated with $55 \mathrm{~mm}$ iodoacetamide in $25 \mathrm{mM} \mathrm{NH}_{4} \mathrm{HCO}_{3}$ at room temperature for $45 \mathrm{~min}$ in the dark, and dehydrated with acetonitrile. Samples were then dried again and digested with $12.5 \mathrm{ng} / \mu \mathrm{L}$ sequencing grade iron deprivation porcine trypsin (Promega, Madison, WI, USA) in $25 \mathrm{mM} \mathrm{NH}_{4} \mathrm{HCO}_{3}$ at $37^{\circ} \mathrm{C}$ overnight. Samples were analyzed by a fuzzy logic feedback control system (FlexAnalysis V3.2, Bruker) equipped with delayed ion extraction. Filtered data were used as queries in MASCOT (Matrix Science, UK) searches against the O.furnacalis fat body transcriptome, which was sequenced and assembled in Majorbio (Shanghai, China) (unpublished).

\section{Sequence Analysis}

The coding sequence (CDS) of Epp1 was used as a query in a Blast search against the genome sequence of $O$. furnacalis (unpublished) to find contigs containing the genome sequence of Epp1. Then, the genomic sequence of Eppl was cloned with specific primers (online suppl. Table 1; for all online suppl. material, see www.karger.com/doi/10.1159/0005515122). PCR amplification using the genomic DNA as a template was performed using the following program: pre-denaturation at $94^{\circ} \mathrm{C}$ for $2 \mathrm{~min}, 35$ cycles of denaturation at $94^{\circ} \mathrm{C}$ for $30 \mathrm{~s}$, annealing at $60^{\circ} \mathrm{C}$ for $30 \mathrm{~s}$, extension at $72^{\circ} \mathrm{C}$ for $1.6 \mathrm{~min}$, and a final extension at $72^{\circ} \mathrm{C}$ for $5 \mathrm{~min}$. Finally, the PCR products were sequenced, and exons and introns were identified by comparing the genomic sequence to the CDS.

Gene and protein sequences of OfEPP1 were used as queries in Blast searches against the National Center for Biotechnology Information (NCBI) database (http://www.ncbi.nlm.gov/- BLAST/) to identify homologs, and the conserved domains were predicted using the Conserved Domain Database (https://www.ncbi.nlm. nih.gov/Structure/cdd/). The CDS of OfEpp1 was analyzed by getorf (http://emboss.bioinformatics.nl/cgi-bin/emboss/getorf). Signal peptide and cleavage site predictions were made using SignalP4.1 (http://www.cbs.dtu.dk/- services/SignalP/). Transmembrane domain prediction was performed in TMHMM (http:// www.cbs.dtu.dk/services/- TMHMM-2.0/). The potential glycosylation sites and phosphorylation sites were predicted using the CBS server (http://cbs.dtu.dk/services/). The theoretical molecular weight was estimated by the Protein Molecular Weight Calculator (http://www.sciencegateway.org/tools/proteinmw.htm).

\section{Prokaryotic Expression of Recombinant OfEPP1 and the}

Preparation of Polyclonal Antibody

A deletion of about 50 to $600 \mathrm{bp}$, which contained most of the repetitive sequences, randomly occurred in the cloned CDS; therefore, a codon-optimized OfEpp1 CDS was chemically synthesized to decrease the repetitive sequence content. Then, the synthesized OfEpp1 cDNA was cloned into the pET-32a vector with a $6 \times \mathrm{His}$ tag at IGE Biotechnology (IGE Bio, Guangzhou, China) and expressed in Escherichia coli strain BL21. The recombinant OfEPP1$6 \times$ His fusion protein was purified using Ni Sepharose excel (GE Healthcare, Fairfield, CT, USA) for further use.

The polyclonal antibodies against OfEPP1 were prepared with purified recombinant OfEPP1 (re-OfEPP1) according to standard procedures at Abmart (Shanghai, China) [35]. Antiserum was precipitated with ammonium sulfate and affinity purified using protein A/G-agarose beads (Millipore, Billerica, MA, USA). Antibody specificity was confirmed by Western blotting, as described previously [36]. Monoclonal antibodies against the His-tag (1:2,000) (Abmart, Shanghai, China) and HRP-conjugated sheep antimouse IgG (1:500, Gene) secondary antibodies were used.

\section{Eukaryotic Expression of OfEPP1}

$R e$-OfEPP1 was expressed using the Bac-to-Bac Baculovirus Expression Vector System and purified, as described previously [19]. The aforementioned chemically synthesized codon-optimized cDNA of OfEpp1 was fused with a C-terminal $6 \times$ his tag and then cloned into the vector $\mathrm{pFastBac}-1$ to generate a recombinant vector; cloning was performed at IGE Biotechnology. After expressed $r$-OfEPP1 was purified with Ni-NTA agarose (Qiagen, Duesseldorf, Germany), imidazole in the elution buffer containing the purified protein was replaced with PBS using a 3-kDa ultrafiltration column (Millipore). The concentration of purified reOfEPP1 was not sufficient for aggregation and spreading analysis; therefore, the expression supernatant was concentrated using a 50$\mathrm{kDa}$ ultrafiltration column (Millipore) for functional analysis.

\section{RT-PCR Analysis}

About 30 Sephadex A-25 beads (Sigma-Aldrich) or $1 \times 10^{6} \mathrm{mi}-$ crobes of E. coli (DH5a), Staphylococcus aureus, or Saccharomyces cerevisiae inactivated with $95 \%$ ethanol in $5 \mu \mathrm{L}$ of PBS were separately injected into each $O$. furnacalis larva on the second day in the fifth instar. At least 30 larvae were injected in each group. Fat bodies and hemocytes were collected separately at 2, 6, and $24 \mathrm{~h}$ after injection, and then, total RNAs were isolated and reversetranscribed. Total RNAs extracted from the hemocytes, fat bodies, midgut, and epidermis of $O$. furnacalis larvae on the second day in the fifth instar were reverse-transcribed into cDNA. Amplification was performed under the following conditions: pre-denaturation 
at $95^{\circ} \mathrm{C}$ for $10 \mathrm{~s}, 30$ cycles of denaturation at $95^{\circ} \mathrm{C}$ for $5 \mathrm{~s}$, annealing at $58^{\circ} \mathrm{C}$ for $15 \mathrm{~s}$, extension at $72^{\circ} \mathrm{C}$ for $20 \mathrm{~s}$, and a final extension at $72^{\circ} \mathrm{C}$ for $10 \mathrm{~min}$. All expression levels were normalized against the reference gene ribosomal protein $\mathrm{S}$. The relative transcript abundance of OfEpp1 was quantified using the comparative $C_{t}\left(2^{-\Delta \Delta C t}\right)$ method. Each qRT-PCR measurement was performed in triplicate and repeated at least 3 times.

\section{RNA Interference}

The dsRNAs targeting OfEpp1 and the green fluorescent protein (GFP) gene were synthesized using the T7 RiboMAX ${ }^{\mathrm{TM}}$ Express RNAi System (Promega) with specific primers (online suppl. Table 1). O. furnacalis larvae on the first day in the fifth instar were anesthetized on ice, and $20 \mu \mathrm{g}$ of $d s O f E p p 1$ or $d s G F P$ in $5 \mu \mathrm{L}$ of diethyl pyrocarbonate-treated water was injected into separate larvae. At least 20 larvae were injected in each group. Total RNAs were extracted from the larvae at $60 \mathrm{~h}$ postinjection to check knockdown efficiency by RT-PCR analysis with specific primers (online suppl. Table 1), as described above. Encapsulation ability of larval hemocytes was analyzed at $60 \mathrm{~h}$ after dsRNA injection, as described in the following section. In each group, at least 6 larvae were analyzed.

\section{Encapsulation Analysis}

To decrease the possible effect of residual plasma on hemocyte function, hemocytes from the hemocyte cell line SYSU-OfHe-C were used for encapsulation analysis, instead of freshly harvested hemocytes. Hemocytic encapsulation was analyzed in $90 \mu \mathrm{L}$ of a suspension containing SYSU-OfHe-C hemocytes $\left(2 \times 10^{6}\right.$ cells/ $\mathrm{mL}$ ) and about 30 Congo Red-stained Sephadex A-25 beads as foreign objects in a 96-cell plate. For plasma-induced promotion of hemocyte spreading on a culture plate, beads were first incubated together with hemocytes for $30 \mathrm{~min}$, and then, different plasma samples or recombinant proteins $(10 \mu \mathrm{L}$ each) were added separately to analyze their encapsulation-promoting ability. After being incubated for $2 \mathrm{~h}$ at room temperature, beads were observed under a microscope (IX71, Olympus, Tokyo, Japan). If more than $50 \%$ of the Sephadex beads were encapsulated by multiple layers of hemocytes in one cell, then the corresponding sample was regarded as possessing encapsulation-promoting ability. PBS, plasma, and heated plasma were used as controls.

For the separation of functional protein, components and fractions of $O$. furnacalis plasma during separation were analyzed. For antibody blocking analysis, O. furnacalis larval plasma was mixed with polyclonal antiserum against OfEPP1 at a volume ratio of 5:1, $1: 1$, or $1: 2$, and then, the mixtures were used for encapsulation analysis, as described above. Laval plasma mixed with pre-immune rabbit serum at a volume ratio of 1:2 was used as a control.

For the functional analysis of $r e$-OfEPP1, $5 \mu \mathrm{g}$ of purified $r e$ OfEPP1 was analyzed, as described above. For the functional analysis of larval plasma without OfEPP1, $100 \mu \mathrm{L}$ of protein A/G-agarose beads (Millipore) was first incubated together with $700 \mu \mathrm{L}$ of rabbit antiserum against OfEPP 1 for $1 \mathrm{~h}$ at room temperature, then collected by centrifugation, and added to $100 \mu \mathrm{L}$ of heated larval plasma for $2 \mathrm{~h}$ to bind OfEPP1. Finally, treated larval plasma was collected for encapsulation analysis, as described above.

For RNAi analysis, about 30-50 Congo Red-stained Sephadex A- 25 beads in $5 \mu \mathrm{L}$ of Pringle's saline were injected into a larva, and then dissected out of the larva at $2 \mathrm{~h}$ after injection. If the bead was encapsulated by more than one layer of hemocytes, encapsulation was classified as multilayer encapsulation.

A Novel Encapsulation-Promoting

Protein in Insect Plasma
Analysis of Aggregation and Spreading of Hemocytes

The effect of re-OfEPP1 on aggregation and spreading of hemocytes was analyzed using $100 \mu \mathrm{L}$ of hemocytes $\left(1 \times 10^{5}\right.$ cells $\left./ \mathrm{mL}\right)$ in 96-cell plates. For the cell line SYSU-OfHe-C, $5 \mu \mathrm{L}$ of expression supernatants containing re-OfEPP1 at concentrations of $0.5,1.5$, 2.5 , and $4.5 \mu \mathrm{g} / \mu \mathrm{L}$ were separately added to the plate cells. For the 2 cell sublines, SYSU-OfHe-C Gr and SYSU-OfHe-C Pl [37], $5 \mu \mathrm{L}$ of supernatant containing re-OfEPP1 at a concentration of 2.5 or $4 \mu \mathrm{g} / \mu \mathrm{L}$ (see details in the section Eukaryotic Expression of OfEPP1) was separately incubated with $\mathrm{Gr}$ or Pl cells for $2 \mathrm{~h}$. Then hemocytic aggregation and spreading within one field of view were observed under a microscope (IX71, Olympus). Spreading hemocytes were phase dark with an irregular shape, and nonspreading hemocytes were phase bright and round under a phase-contrast microscope. During proliferation of hemocytes, several cells (no more than eight) sometimes adhered together; therefore, a cluster of more than eight cells was regarded as an aggregate. At least 5 fields of view were observed for each sample.

\section{Localization of re-OfEPP1 in Hemocytes}

Hemocytes $(50 \mu \mathrm{L})$ from SYSU-OfHe-C $\left(1 \times 10^{5}\right.$ cells $\left./ \mathrm{mL}\right)$ were dropped on a slide and allowed to spread for $1 \mathrm{~h}$, then incubated together with $5 \mu \mathrm{g}$ of eukaryotically or prokaryotically expressed re-OfEPP1 in $20 \mu \mathrm{L}$ PBS for $1 \mathrm{~h}$, and washed with PBS at least 3 times to get rid of residual re-OfEPP1. Then, cells were fixed with $4 \%$ paraformaldehyde for $1 \mathrm{~h}$, blocked with $8 \%$ FBS in PBS for $1 \mathrm{~h}$, and incubated together with monoclonal mouse antibody against His $(1: 1,000)$ (TransGene Biotech, Beijing, China) for $1 \mathrm{~h}$, and Alexa Fluor 488 donkey anti-mouse IgG $(\mathrm{H}+\mathrm{L})(1: 250)$ (Thermo Fisher) for $1 \mathrm{~h}$. Cells incubated together with $10 \%$ (v/v) larval plasma in $20 \mu \mathrm{L}$ PBS were used as a control. Finally, trypan blue $(0.4 \%$, $\mathrm{w} / \mathrm{v}$ ) was used to quench extracellular fluorescence and autofluorescence of hemocytes, which were further observed under a fluorescence microscope (IX 71, Olympus).

\section{Statistical Analysis}

All data were analyzed with a statistical significance level of $p<$ 0.05 using $t$-tests in SPSS 17.0 software (SPSS Inc., Chicago, IL). All proportional data were transformed by arcsine square root before analysis. Statistical charts were created by GraphPad Prism 8.

\section{Results}

\section{Thermally Stable Encapsulation-Promoting Factors}

Exist in the Plasma of O. furnacalis Larvae

Hemocytes of $O$. furnacalis are composed of 5 subpopulations, and $90 \%$ of them are immune cells (granulocytes and plasmatocytes) participating in cellular immune reactions [34]. The cell line SYSU-OfHe C is also mainly composed of granulocytes and plasmatocytes [29]. Hemocytes from SYSU-OfHe C do not encapsulate Sephadex A-25 beads introduced as foreign objects; however, when $5 \%$ (v/v) larval plasma is supplied, about $90 \%$ of the beads are encapsulated by hemocytes [32] (Fig. 1a, b), indicating that some encapsulation-promoting factors 


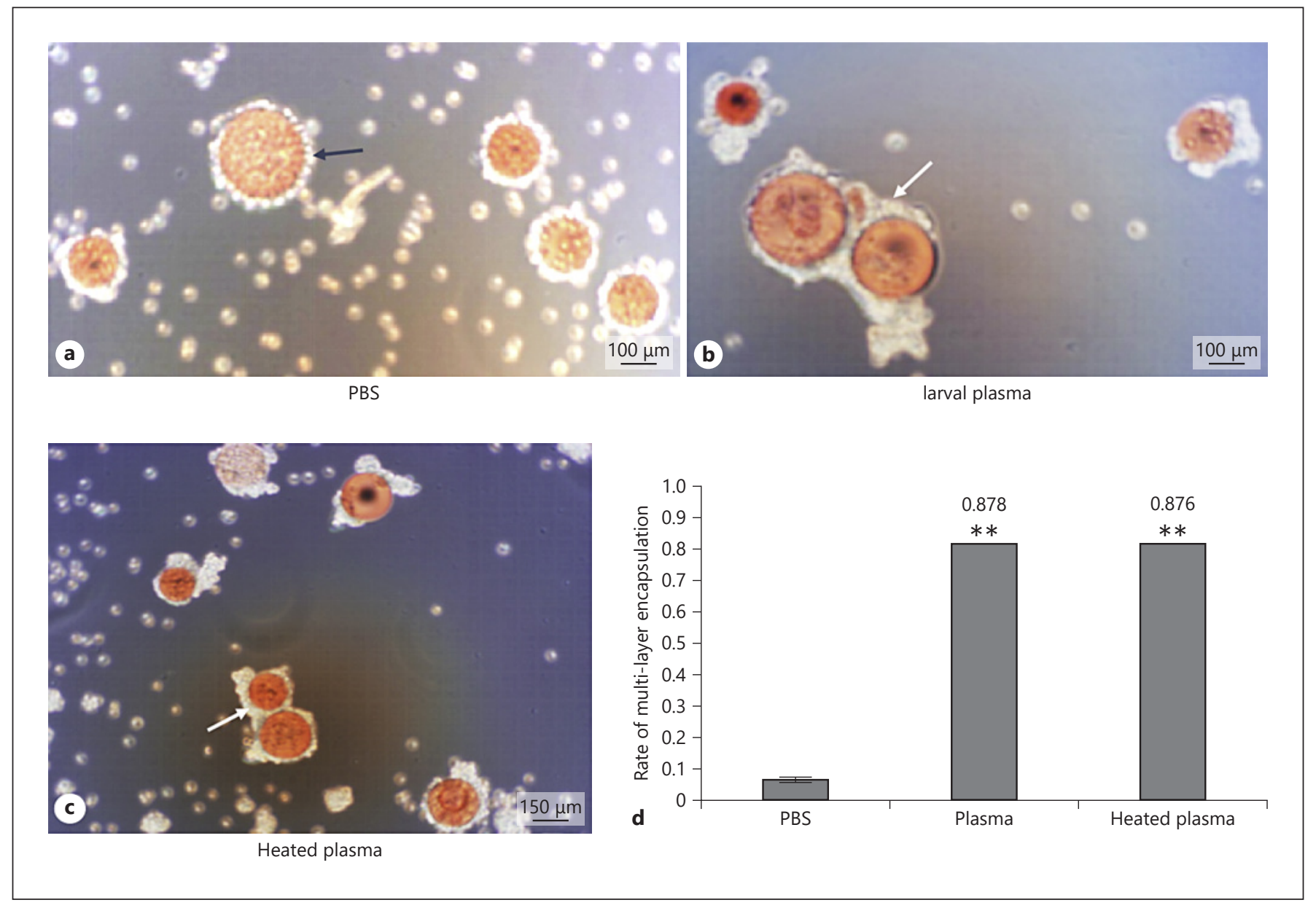

Fig. 1. Analysis of the encapsulation-promoting function of heated larval plasma of O. furnacalis. a PBS (negative control). b 5\% (v/v) unheated larval plasma (positive control). c $5 \%$ heated larval plasma. Black arrow indicates a single layer of hemocytes on beads, and white arrows indicate multilayer hemocytic encapsulation around beads. $\mathbf{d}$ Proportions of Sephadex beads encapsulated by multiple layers of hemocytes. Data are compiled from at least 3 independent experiments, each experiment being performed in triplicate (mean \pm SEM). ${ }^{* *} p<0.001$ ( $t$ test $)$. exist in the plasma of $O$. furnacalis. Furthermore, after $O$. furnacalis larval plasma was heated at $100^{\circ} \mathrm{C}$ for $5 \mathrm{~min}$, it still induced hemocytes to encapsulate about $90 \%$ of Sephadex A-25 beads (Fig. 1c, d), suggesting that the encapsulation-promoting factors in plasma are thermostable.

Isolation and Identification of a Novel EncapsulationPromoting Protein in the Plasma of O. furnacalis

Larval plasma without heat-denatured protein was first separated into 14 fractions by RP HPLC. Encapsulation analysis showed that only one of the 14 fractions induced hemocytes to encapsulate more than $50 \%$ of Sephadex A-25 beads (Fig. 2a). The active fraction was then further separated using 2 different methods: RP HPLC and gel filtration. One active fraction (I) among 10 in the second HPLC separation (Fig. 2b, d) and 2 active fractions (II and III) among 7 from gel filtration separation (Fig. 2c, d) were obtained. Furthermore, one protein (about $65 \mathrm{kDa}$ ) that was present in both fractions I and II in SDS-PAGE analysis (Fig. 3a) was analyzed with MS, and a 26 -amino acid fragment was identified (Fig. 3b). In a Tblastn search against the transcriptome of fat bodies from $O$. furnacalis larvae (unpublished), the fragment matched a 1,634-bp transcript containing a 1,443-bp CDS, which was named encapsulation-promoting protein 1 (OfEpp1, GenBank accession number: MG934570) (Fig. 3b). OfEpp1 is not homologous to any known gene in the NCBI database, indicating that it is a novel gene existing only in O. furnacalis to date. A contig containing the OfEPp 1 sequence was found in the genome of $O$. fur- 


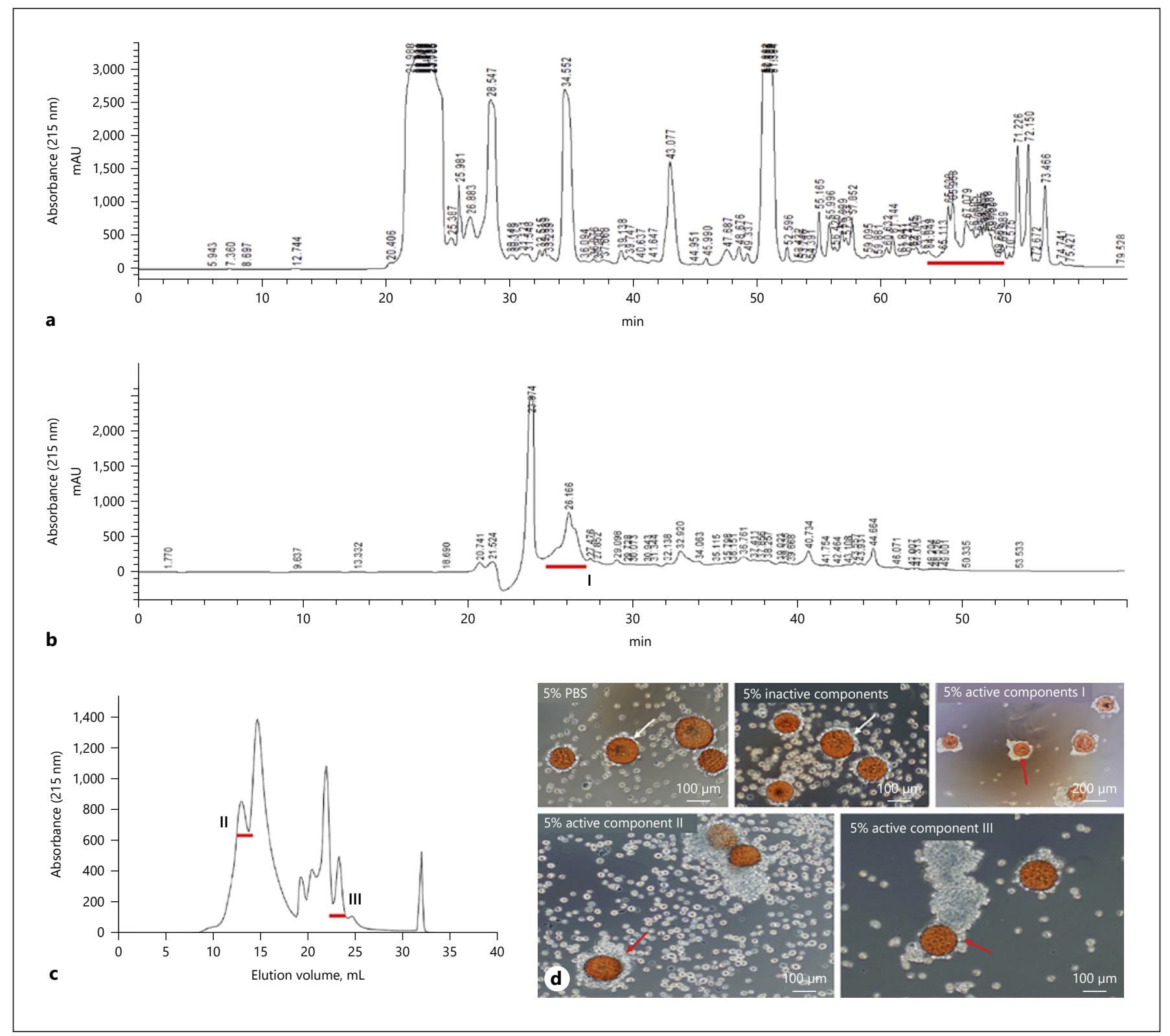

Fig. 2. Separation of OfEPP1 from O. furnacalis larval plasma. a First separation of plasma by RP HPLC. Solid red line indicates the active fraction functioning in encapsulation. $\mathbf{b}$ Second separation of the active fraction in (a) by RP-HPLC. I indicates the active component identified in this separation step. c Second separation of the active fraction in (a) by gel filtration. II and III indicate the active components identified in this separation step. $\mathbf{d}$ The functional analyses of 3 active components and one randomly selected inactive component. White arrows indicate the single-layer hemocytes on beads, and red arrows indicate multilayer hemocytic encapsulation around beads. RP, reverse phase. nacalis (unpublished). Analysis of the genomic sequence of OfEPp1, which was confirmed by sequencing, showed that OfEpp1 possesses only one exon and no intron (Fig. 3d).

OfEPP1 is composed of 481 amino acids, and the theoretical molecular weight is $54.5 \mathrm{kDa}$; however, the mo- lecular weight of OfEPP1 in plasma was about $65 \mathrm{kDa}$, as determined by Western blot analysis (Fig. 3a), indicating the existence of posttranscriptional modifications. Consistent with this, OfEPP1 was predicted to contain 27 glycosylation sites (17 N-glycosylation sites and $10 \mathrm{O}$-glycosylation sites) and 49 phosphorylation sites (Fig. 3b). A 


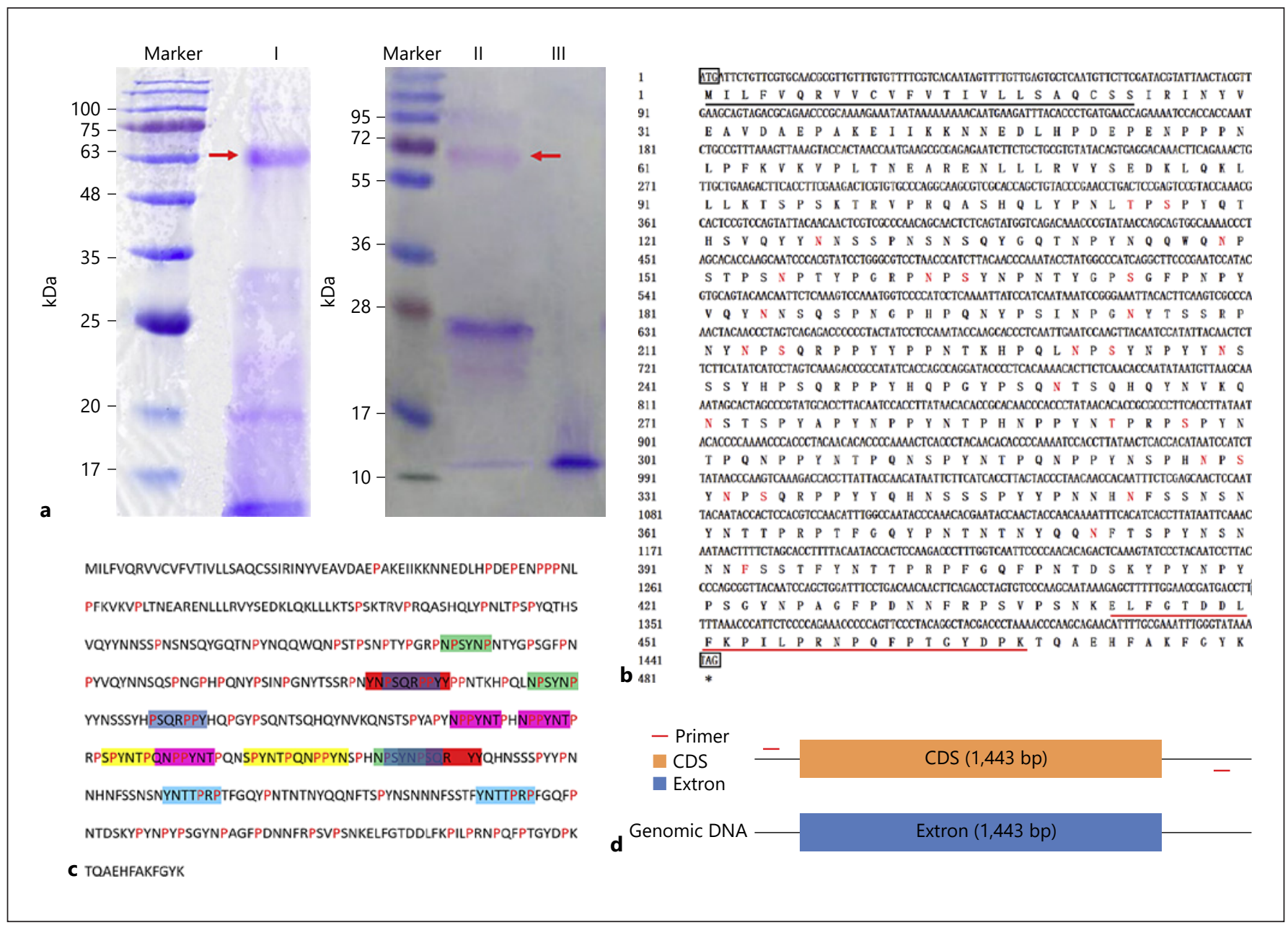

Fig. 3. Identification and structure of OfEPP1. a Separations of 3 active components by SDS-PAGE. Red arrows indicate the proteins present in 2 different separations. The protein band in lane I was further analyzed by MS. I, II, and III indicate the 3 active components. b Nucleotide and amino acid sequences of OfEPP1. Red line indicates the sequence acquired in MS analysis. Black line in- dicates the putative signal peptide of OfEPP1, and the cleavage site is located between amino acids 24 and 25. Potential N-glycosylation $(\mathrm{N})$ and $\mathrm{O}$-glycosylation $(\mathrm{S}$ and $\mathrm{T})$ sites are shown in red. c Repetitive sequences of OfEPP1 (in different back colors) and the proportion of proline residues (in red). d Genomic DNA of OfEPP1. striking feature of the OfEPP1 sequence is that it contains 6 groups of repetitive sequences longer than $6 \mathrm{bp}$ (two SPYNTPQNPPYN, two YNTTPRP, two YNPSQRPPYY, three PSQRPPY, three NPSYNP, and two NPPYNT) (Fig. 3c). Moreover, it contains 88 proline residues, accounting for $18.3 \%$ of all amino acids (Fig. 3c). No conserved domain was identified.

\section{OfEPP1 Is an Inducible Secretory Protein Expressed Mainly in Fat Bodies}

RT-PCR results showed that OfEpp1 was mainly expressed in fat bodies and also weakly expressed in hemocytes and the epidermis (Fig. 4a). OfEPP1 has a 24-bp signal peptide that is cleaved after Ser 24 (Fig. 3b), but it does not have a transmembrane domain, so it is likely a secretory protein. Western blotting results revealed a large quantity of OfEPP1 in larval plasma but not in fat bodies or hemocytes (Fig. 4b), confirming that OfEPP1 is a secretory protein and is secreted in hemolymph by tissues. Next, the expression of OfEPp1 in fat bodies and hemocytes was analyzed after injection of $O$. furnacalis larvae with Sephadex A-25 beads or one of 3 types of microbes, E. coli $\left(\mathrm{Gram}^{-}\right)$, S. aureus $\left(\mathrm{Gram}^{+}\right)$, and S. cerevisiae (yeast) (Fig. 4c and online suppl. Fig. 1). The expression levels of OfEpp1 in fat bodies, hemocytes, and the epidermis were higher than those in the control (larvae 


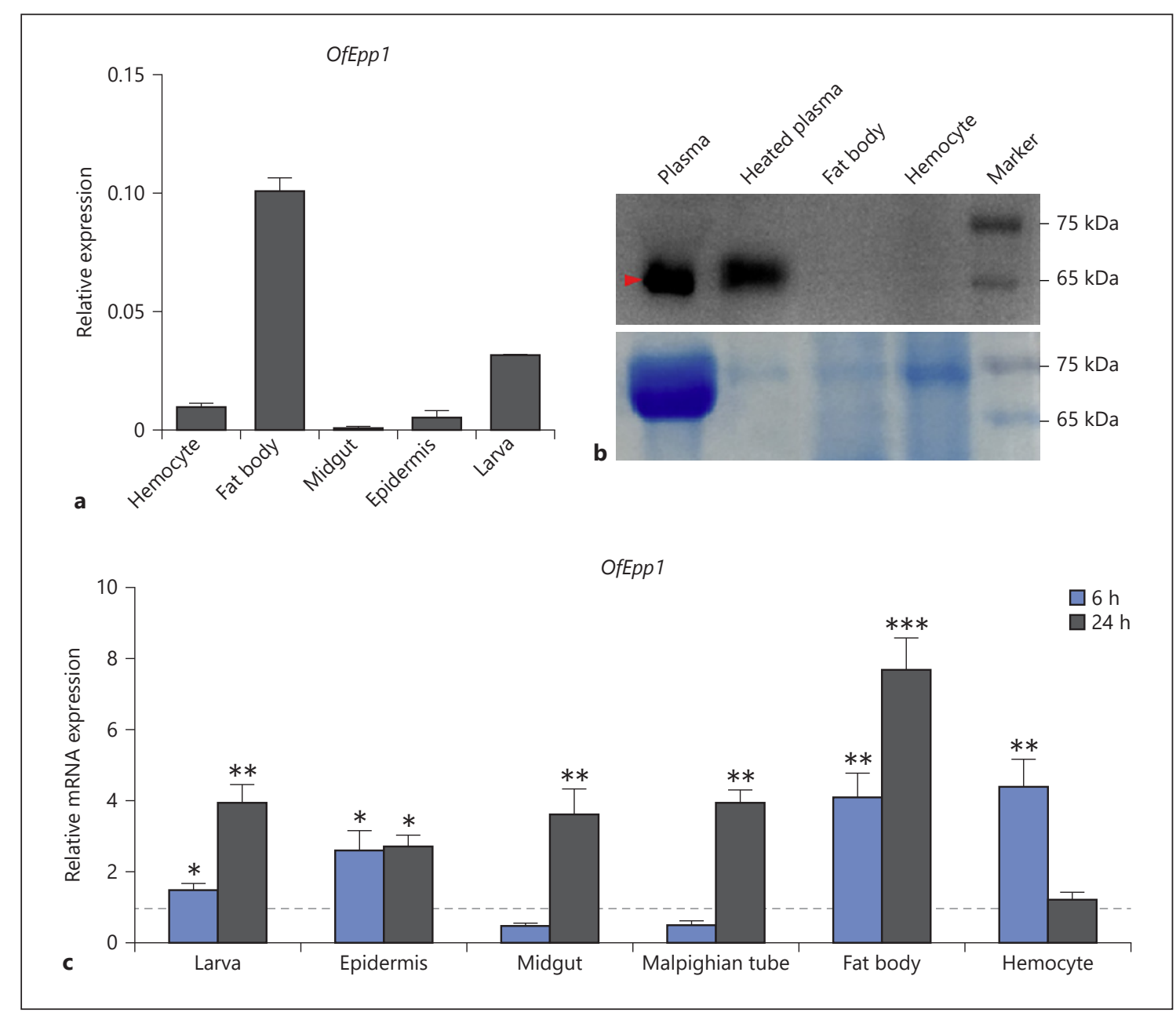

Fig. 4. Expression of $O f E P P 1$ at the mRNA and protein levels in $O$. furnacalis larvae. a qRT-PCR analysis of OfEpp1 in different tissues and larvae. Each experiment is performed in triplicate (mean \pm SEM). b Western blotting (up) and SDS-PAGE (down) analysis of OfEPP1 in different tissues. Red triangle indicates OfEPP1. c Ex- pression levels of OfEpp1 in larvae provoked by Sephadex A-25 beads at 6 and $24 \mathrm{~h}$ relative to $2 \mathrm{~h}$ (broken line). Data are compiled from at least 3 independent experiments, and each experiment is performed in triplicate (mean $\pm \mathrm{SEM}$ ). ${ }^{*} p<0.05,{ }^{* *} p<0.01$, ${ }^{* * *} p<0.001,(t$-test $)$. injected with PBS) at $6 \mathrm{~h}$ after bead injection, and the expression levels were significantly higher than those in the control in all tissues, except hemocytes at $24 \mathrm{~h}$ after injection, especially in fat bodies $(p<0.001)$ (Fig. $4 c)$. However, the level of OfEpp1 in fat bodies did not significantly change within $6 \mathrm{~h}$ after the injection of microbes, but increased expression was observed at $24 \mathrm{~h}$ after the injection of E. coli (online suppl. Fig. 1, left panel). The expression level of OfEpp1 in hemocytes was about 10 times lower than that in fat bodies, and it did not sharply increase in larvae injected with microbes, except for $S$. aureus at $6 \mathrm{~h}$ (online suppl. Fig. 1, right panel). All these results indicated that $O f E p p 1$ is mainly expressed in fat bodies and is induced by Sephadex beads but not E. coli, S. aureus, or yeast.

\section{Eukaryotically Expressed OfEPP1 Promotes Hemocyte} Encapsulation of Sephadex Beads

Western blot analysis showed that the molecular weight of re-OfEPP1 fused with a His-tag (re-OfEPP1) was about $70 \mathrm{kDa}$ (Fig. 5a, right panel). Encapsulation analysis showed that eukaryotically expressed re-OfEPP1, like larval plasma, promoted more encapsulation of Sephadex A-25 beads than the PBS control (Fig. 5b). Some aggregation occurred in hemocytes supplied with reOfEPP1 (Fig. 5b). To confirm the encapsulation-promot- 


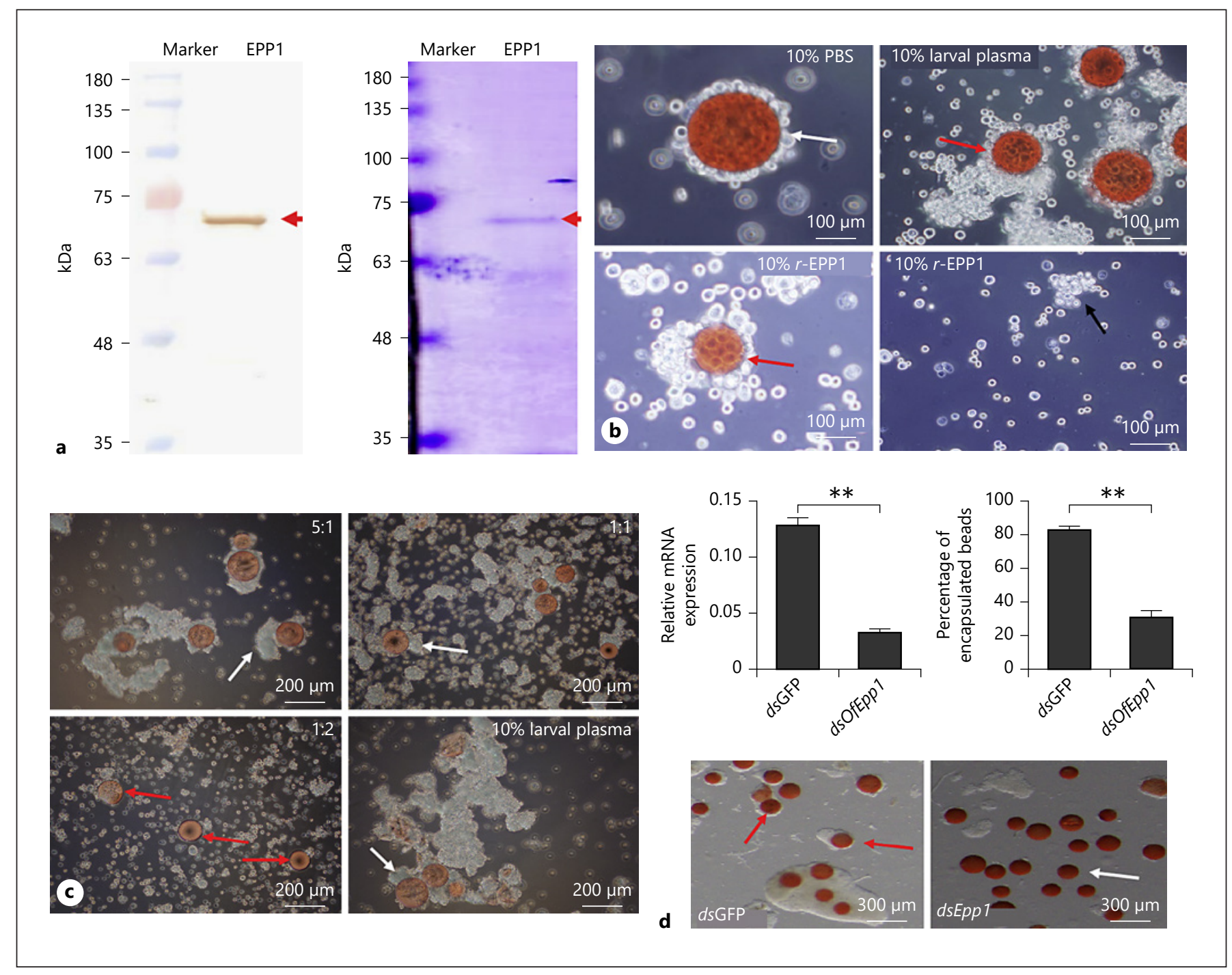

Fig. 5. OfEPP1 promoted hemocytic encapsulation of Sephadex A-25 beads. a Eukaryotically expressed OfEPP1 in SDS-PAGE (right) and Western blotting (left) analysis. Red arrows indicate OfEPP1. b Functional analysis of re-OfEPP1. 10\% (v/v) re-OfEPP1 $(5 \mu \mathrm{g})$, larval plasma, and PBS were analyzed. White arrow indicates a single layer of hemocytes on beads, red arrows indicate multilayer hemocytic encapsulation around beads, and black arrow indicates the aggregation of hemocytes. c Functional analysis of anti-OfEPP1 serum. White arrows indicate multilayer hemo-

ing function of OfEPP1, polyclonal antibodies against OfEPP1 (anti-OfEPP1) were prepared and used to neutralize OfEPP1 in larval plasma. When larval plasma was mixed with anti-OfEPP1 serum at a ratio of 5:1, no significant effect on encapsulation was observed, and about $90 \%$ beads were fully encapsulated, the same percentage observed for larval plasma (Fig. 5c). In contrast, when the ratio was $1: 1$, the encapsulation-promoting function cytic encapuslation around beads, and red arrows indicate the unencapsulated or partially encapsulated beads. d RNAi analysis. Expression of OfEpp 1 in larval fat bodies (left), and the percentage of encapsulation of Sephadex A-25 beads (right). Data are compiled from at least 3 independent experiments, and each experiment is performed in triplicate (mean \pm SEM). ${ }^{* *} p<0.01$ ( $t$ test). The encapsulation of Sephadex beads in each treatment are shown (below).

slightly decreased; some beads were not completely encapsulated, and some capsules extended only in one direction (Fig. 5c). When the ratio was 1:2, the encapsulation-promoting function was inhibited; only part of the surface of beads was covered by multiple layers of hemocytes (Fig. 5c). Laval plasma, mixed with $2 \times$ volume of pre-immune rabbit serum as a control, promoted hemocytic encapsulation to the same extent as larval plasma 

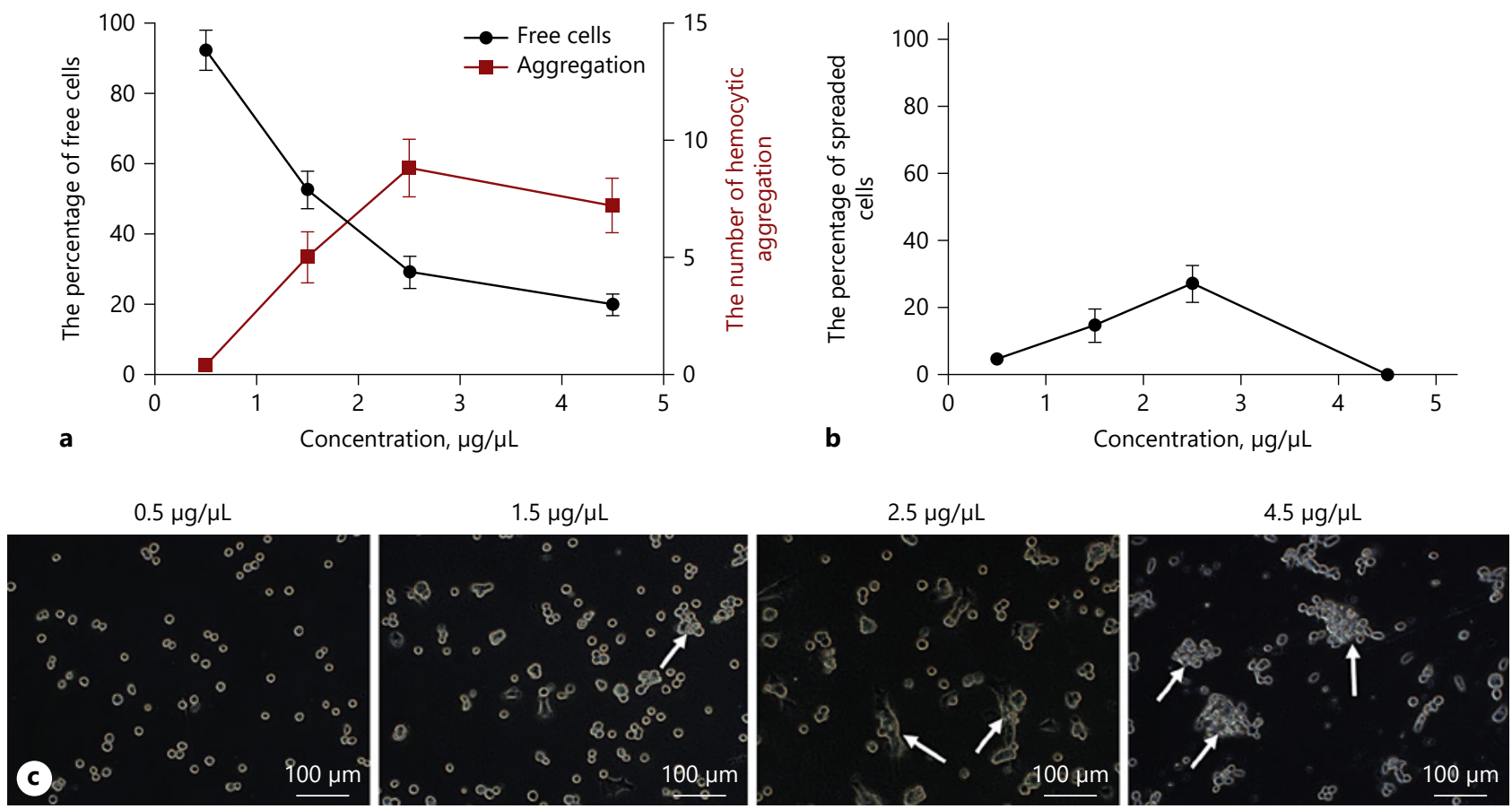

Fig. 6. Analysis of the effect of re-OfEPP1 on aggregation and spreading of hemocytes in cell line SYSU-OfHe-C. a Percentage of free cells and the number of hemocytic aggregates. $\mathbf{b}$ Percentage of spreading cells. Each point represents mean \pm SEM from 3 bio- logical replicates. c Aggregation of hemocytes at different concentrations of re-OfEPP1. White arrows indicate the aggregation of hemocytes. re-OfEPP1, recombinant OfEPP1.
(Fig. 5c). These results indicated that anti-OfEPP1 serum inhibited the encapsulation-promoting function of OfEPP1. Furthermore, the encapsulation-promoting function of OfEPP1 was confirmed by RNAi in O. furnacalis larvae. RT-PCR results showed that the expression of OfEpp1 in dsOfEpp1-injected larvae decreased significantly compared with that in $d s G F P$-injected larvae at $60 \mathrm{~h}$ after injection (Fig. 5d, left panel). In dsOfEpp1-injected larvae, only about $30 \%$ of beads were encapsulated by hemocytes, whereas about $80 \%$ of beads were encapsulated in dsGFP-injected control larvae (Fig. 5d, right panel and panel below). To understand the effect of posttranslational modification on the function of OfEPP1, reOfEPP1 was expressed in E. coli (online suppl. Fig. 2, panel above). Encapsulation analysis showed that the prokaryotically expressed re-OfEPP1 did not promote hemocytic encapsulation, and, as in the PBS treatment control, no beads were encapsulated by multiple layers of hemocytes (online suppl. Fig. 2, panel below), indicating that posttranslational modification is important for the function of OfEPP1. These results indicated that OfEPP1 plays an important role in regulating hemocytic encapsulation.

\section{OfEPP1 Promotes Hemocyte Aggregation by Binding} to the Surface of Hemocytes

Analysis of aggregation and spreading showed that OfEPP1 promoted the aggregation of hemocytes in a dose-dependent manner. With an increase in the amount of re-OfEPP1, more hemocytes aggregated together, and the number of free cells decreased. At a concentration of $4.5 \mu \mathrm{g} / \mu \mathrm{L}$, fewer than $20 \%$ of hemocytes were free, and the aggregates were larger than those at lower concentrations of re-OfEPP1 (Fig. 6a, c). However, OfEPP1 did not significantly promote spreading of hemocytes. No more than $30 \%$ of hemocytes spread at concentrations ranging from 0.5 to $2.5 \mu \mathrm{g} / \mu \mathrm{L}$, and few hemocytes spread at a concentration of $4.5 \mu \mathrm{g} / \mu \mathrm{L}$ (Fig. 6b, c), indicating that OfEPP1 possibly functions more in the aggregation than spreading of hemocytes. 


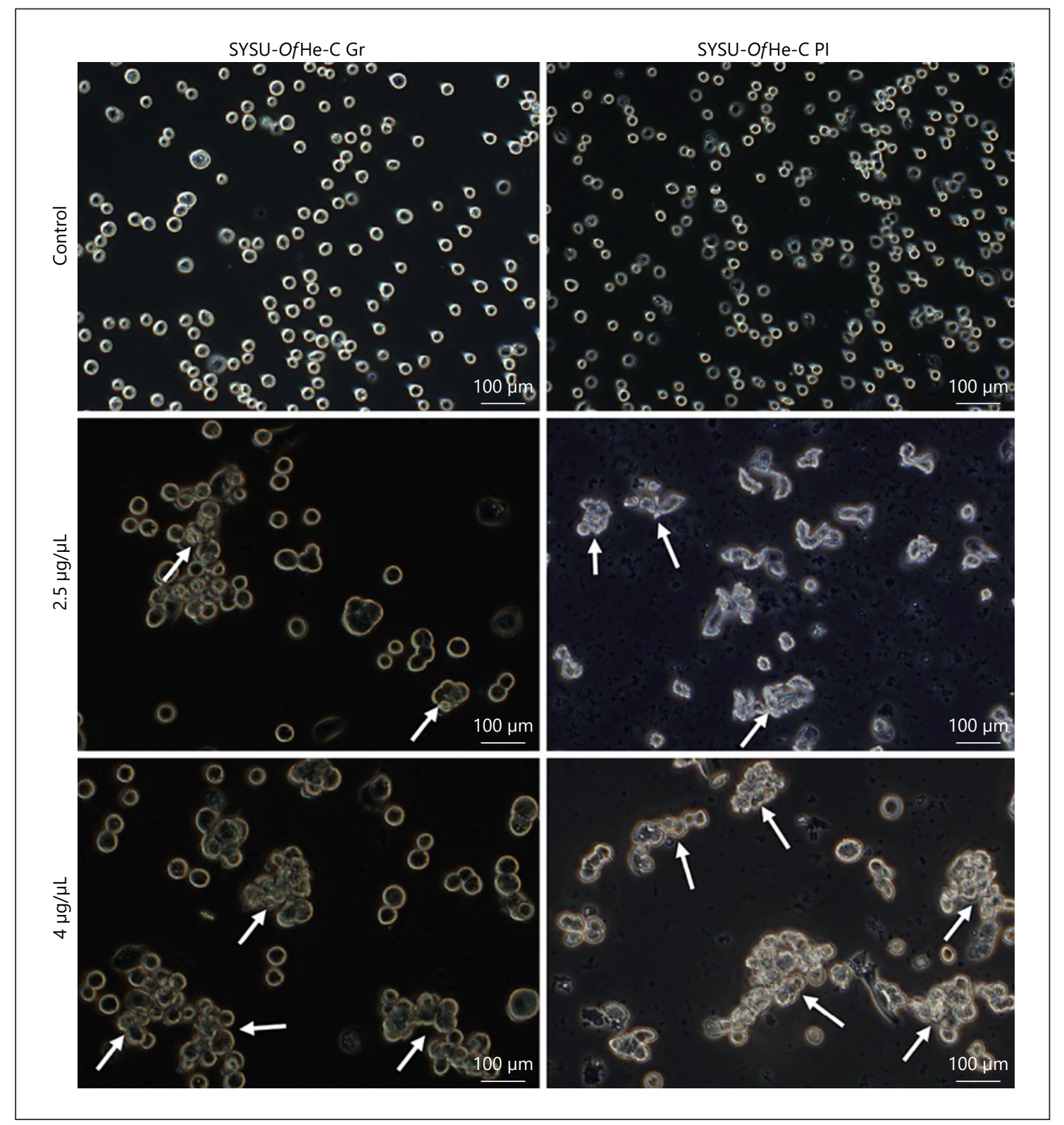

Fig. 7. Analysis of the aggregation of hemocytes from 2 cell sublines $\mathrm{Gr}$ and $\mathrm{Pl}$ at the presence of eukaryotically expressed re-OfEPP1. White arrows indicate the aggregation of hemocytes. re-OfEPP1, recombinant OfEPP1.

Next, the effects of OfEPP1 on 2 cell sublines, SYSUOfHe-C Gr and SYSU-OfHe-C Pl, which possess granulocytes and plasmatocytes, respectively, were analyzed. The results showed that OfEPP1 increased the aggregation of both $\mathrm{Gr}$ and $\mathrm{Pl}$ cells compared with the PBS control. More than half of the cells began to aggregate at a concentration of $2.5 \mu \mathrm{g} / \mu \mathrm{L}$, and more than $80 \%$ of hemocytes aggregated at a concentration of $4.5 \mu \mathrm{g} / \mu \mathrm{L}$ (Fig. 7).
The shapes of the Pl cells changed, while the Gr cells remained round (Fig. 7). Immunocytochemistry analysis showed that eukaryotically expressed $r e$-OfEPP1 could be detected on the surface of a portion of hemocytes, including granulocytes and plasmatocytes, while the prokaryotically expressed re-OfEPP1 could not (Fig. 8), indicating that posttranscriptional modification of OfEPP1 is important for its binding to hemocytes and function. 


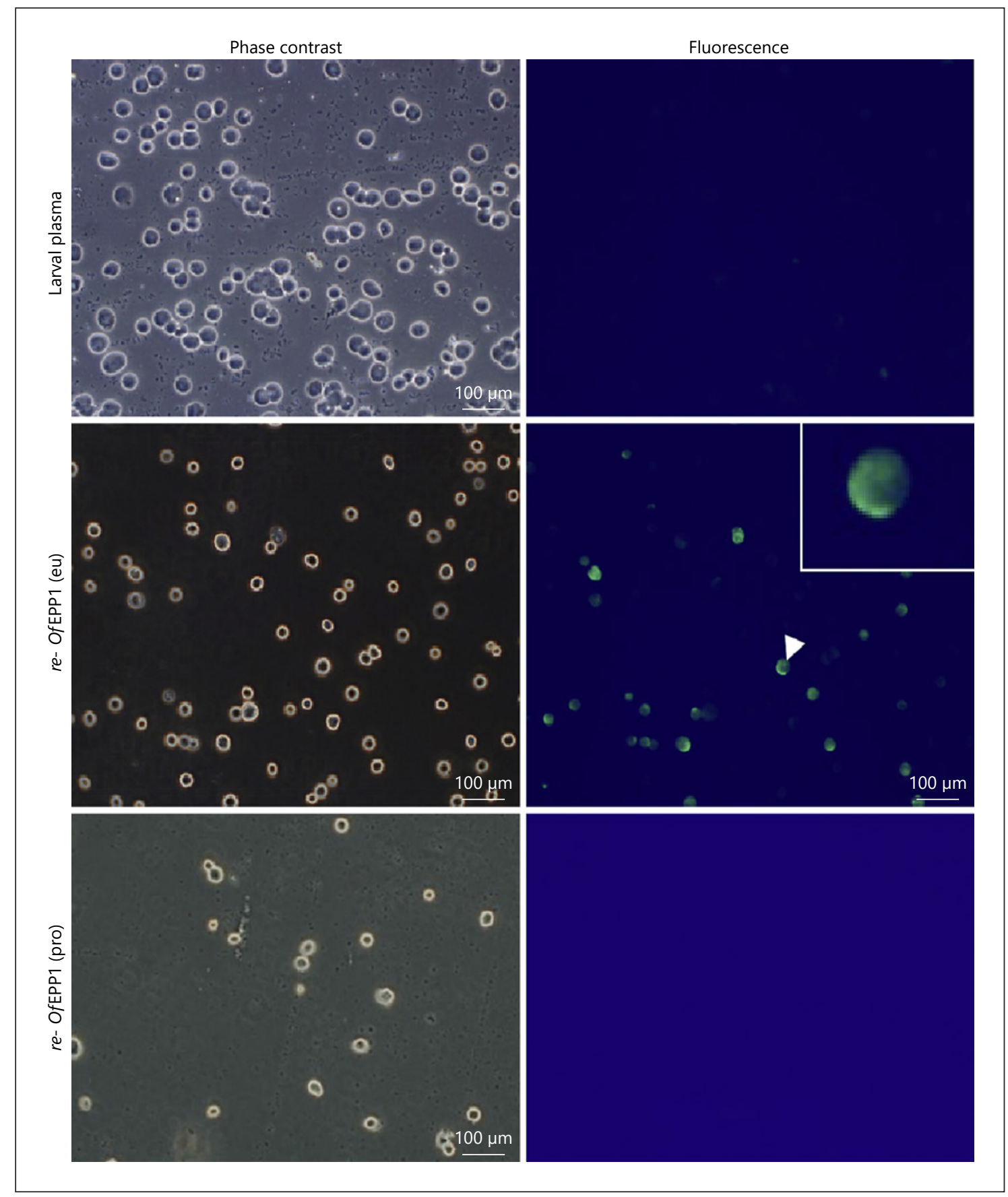

Fig. 8. Immunocytochemistry detection of re-OfEPP1 on the surface of SYSU-OfHe-C hemocytes. The white triangle indicates the hemocytes bound with re-OfEPP1, which is magnified and shown in the white rectangle. reOfEPP1, recombinant OfEPP1.

Taken together, these results indicate that OfEPP1 possibly binds to the surface of hemocytes to induce their aggregation and further promote the encapsulation of foreign objects.

A Novel Encapsulation-Promoting Protein in Insect Plasma

\section{Discussion}

A protein named OfEPP1 that functions in promoting encapsulation was isolated from larval plasma of O. fur-

Innate Immun 2021;13:280-294 
nacalis using the hemocytic cell line SYSU-OfHe C [32]. No homolog of OfEPP1 was identified in the NCBI database and the genomes of several lepidopteran insects (data not shown), so it is a novel protein that has only been found in O. furnacalis to date. OfEpp 1 is an intronless (single exon) gene, and there are 2 copies adjacent to each other in the genome (data not shown). Few intronless genes and their functions have been reported, especially in insects to date $[38,39]$. As one of the few known single exon genes with immune function, OfEppl may possibly be helpful in studying the origin and evolution of intronless genes in insects.

OfEPP1 contains 6 groups of short repetitive sequences of more than $6 \mathrm{bp}$ in length. Few studies on the function of repetitive peptides such as these have been reported to date. A hemocytic coagulation-related protein, fondue, in Drosophila also contains several similar repeat blocks, but the repetitive amino acid sequences are different from those in EPP1, and the functions of these repetitive sequences were not analyzed [40]. OfEPP1 is a thermally stable secretory protein consisting of $18.3 \%$ proline residues, and this high proline content is possibly related to its thermostability. Proline can cause the peptide to bend sharply and make it easier for the peptide chain to form hydrogen bonds with the polar side chains of amino acids, thus reducing the flexibility of the peptide skeleton and stabilizing the protein structure. In addition, the hydrophobic side chains of proline can be tightly wrapped by adjacent hydrophobic cavities, which makes irregular coiling or B transition structures more stable, and further strengthens the stability of the protein space structure $[41,42]$. Posttranslational modifications are also likely important for the function of OfEPP1. OfEPP1 contains 17 potential N-glycosylation sites and 10 potential O-glycosylation sites. The aggregation of hemocytes involves the formation of connections between cells, and protein modifications such as glycosylation possibly play an important role during these processes. The posttranslational modifications of a hemocytic aggregation-related peptide, HCP, were also reported to affect its activity in $P$. includens [43].

The molecular mechanism of encapsulation is still unclear. Spreading has been shown to play an important role during encapsulation, and hemocytes change their state from nonadhesive to adhesive before encapsulating foreign objects $[2,3,44]$. However, we found that OfEPP1 mainly promotes encapsulation by mediating hemocyte aggregation but not spreading, indicating that 2 dependent processes, aggregation and spreading of hemocytes, are involved in encapsulation in insects. Compared with the Toll and Imd pathways, which are involved in insect humoral immunity, much less is known about how nonself signals are transduced to hemocytes in insect cellular immunity. The function of OfEPP1 is possibly to recruit more hemocytes around foreign objects and then to promote encapsulation. Several factors related to hemocyte aggregation have already been identified in other insects and were found to be mainly involved in clotting and nodulation. In P. separata, the peptide HCP mediates the aggregation of hemocytes and enhances clotting at wound sites in larvae [43]. In B. mori, hemocytin, an ortholog of von Willebrand factor, mediates hemocytic aggregation and plays a major role in nodule formation [45]. In $M$. sexta, neuroglian participates in the aggregation of hemocytes, and neuroglian-positive plasmatocytes induce the formation of stable hemocyte aggregates [46]. However, the signals that induce the expression of hemocytic aggregation-related factors are still unknown. More studies are needed to clarify the molecular mechanism of hemocyte aggregation and its function in encapsulation.

OfEPP1 binds to the surface of some hemocytes including granulocytes and plasmatocytes to promote encapsulation. However, to date, the functions of these 2 types of hemocytes in encapsulation in O. furnacalis are still poorly understood. Our previous study showed that granulocytes or plasmatocytes alone could encapsulate a few types of foreign objects in the presence of larval plasma [37]. Therefore, both types of hemocytes possibly participate in the construction of capsules in O. furnacalis. Several known encapsulation-related factors such as PSP [9] and IMLs can also bind to hemocytes $[14,17,18]$. The receptor of one IML was identified as integrin [20], which has been shown to mediate hemocyte encapsulation in several insects [47-49]. Integrin $\beta$ on hemocytes of $O$. furnacalis has also been shown to mediate encapsulation [47]. The receptor of OfEPP1 on hemocytes still remains to be identified.

\section{Statement of Ethics}

Animal welfare and experimental procedures were carried out in accordance with the Guide for the Care and Use of Laboratory Animals (Ministry of Science and Technology of China, 2006).

\section{Conflict of Interest Statement}

The authors have no conflicts of interest to declare. 


\section{Funding Sources}

This work was supported by the National Key R\&D Program of China [2017YFD200400], the National Natural Science Foundation of China [32072484, 31272091], the Key Project of Chinese National Programs for Fundamental Research and Development [2013CB127603], the Special Foundation for Key Research Program of Guangzhou (Grant No. 201804020062), Guangdong Basic and Applied Basic Research Foundation [2020A1515010455], and the International Foundation for Science [C3680-2].

\section{Author Contributions}

J. Hu and X. Feng planned and designed the research. X. Feng, L. Yao, M. Meng, Y. Du, Z. Song, Y. Dong, M. Tian, and Y. Chen performed the experiments and analyzed the data. J. Hu wrote the manuscript.

\section{References}

1 Strand MR, Pech LL. Immunological basis for compatibility in parasitoid-host relationships. Annu Rev Entomol. 1995 Jan;40:31-56.

2 Lavine MD, Strand MR. Insect hemocytes and their role in immunity. Insect Biochem Mol Biol. 2002 Oct;32(10):1295-309.

3 Pech LL, Strand MR. Granular cells are required for encapsulation of foreign targets by insect haemocytes. J Cell Sci. 1996 Aug;109(Pt 8):2053-60.

4 Wiegand C, Levin D, Gillespie J, Willott E, Kanost M, Trenczek T. Monoclonal antibody MS13 identifies a plasmatocyte membrane protein and inhibits encapsulation and spreading reactions of Manduca sexta hemocytes. Arch Insect Biochem Physiol. 2000 Nov;45(3):95-108.

5 Davies DH, Hayes TK, Vinson SB. Preliminary characterization and purification of in vitro encapsulation promoting factor: a peptide that mediates insect haemocyte adhesion. Dev Comp Immunol. 1988 Spr;12(2):241-53.

6 Clark KD, Pech LL, Strand MR. Isolation and identification of a plasmatocyte-spreading peptide from the hemolymph of the lepidopteran insect Pseudoplusia includens. J Biol Chem. 1997 Sep;272(37):23440-7.

7 Zhang S, Clark KD, Strand MR. The protein P23 identifies capsule-forming plasmatocytes in the moth Pseudoplusia includens. Dev Comp Immunol. 2011 Apr;35(4):501-10.

8 Clark KD, Volkman BF, Thoetkiattikul H, Hayakawa Y, Strand MR. N-terminal residues of plasmatocyte-spreading peptide possess specific determinants required for biological activity. J Biol Chem. 2001 Oct;276(40): 37431-5.

9 Clark KD, Volkman BF, Thoetkiattikul H, King D, Hayakawa Y, Strand MR. Alaninescanning mutagenesis of plasmatocyte spreading peptide identifies critical residues for biological activity. J Biol Chem. 2001May; 276(21):18491-6.

10 Clark KD, Garczynski SF, Arora A, Crim JW, Strand MR. Specific residues in plasmatocytespreading peptide are required for receptor binding and functional antagonism of insect immune cells. J Biol Chem. 2004 Aug;279(32): 33246-52.

11 Hayakawa Y. Juvenile hormone esterase activity repressive factor in the plasma of para- sitized insect larvae. J Biol Chem. 1990 Jul; 265(19):10813-6.

12 Strand MR, Hayakawa Y, Clark KD. Plasmatocyte spreading peptide (PSP1) and growth blocking peptide (GBP) are multifunctional homologs. J Insect Physiol. 2000 May;46(5):817-24.

13 Matsumoto Y, Oda Y, Uryu M, Hayakawa Y. Insect cytokine growth-blocking peptide triggers a termination system of cellular immunity by inducing its binding protein. J Biol Chem. 2003 Oct;278(40):38579-85.

14 Zhuo XR, Chen L, Wang GJ, Liu XS, Wang YF, Liu K, et al. 20-Hydroxyecdysone promotes release of GBP-binding protein from oenocytoids to suppress hemocytic encapsulation. Insect Biochem Mol Biol. 2018 Jan;92: 53-64.

$15 \mathrm{Yu}$ XQ, Kanost MR. Immulectin-2, a pattern recognition receptor that stimulates hemocyte encapsulation and melanization in the tobacco hornworm, Manduca sexta. Dev Comp Immunol. 2004 Jul;28(9):891-900.

16 Ling E, Yu XQ. Cellular encapsulation and melanization are enhanced by immulectins, pattern recognition receptors from the tobacco hornworm Manduca sexta. Dev Comp Immunol. 2006;30(3):289-99.

17 Ishihara T, Maruyama Y, Furukawa S. Gene expression and molecular characterization of a novel C-type lectin, encapsulation promoting lectin (EPL), in the rice armyworm, Mythimna separata. Insect Biochem Mol Biol. 2017 Oct; $89: 51-7$.

18 Wang XY, Bai SF, Li X, An SH, Yin XM, Li XC. Differential responses of Helicoverpa armigera C-type immunlectin genes to the endoparasitoid Campoletis chlorideae. Arch Insect Biochem Physiol. 2017 Mar;94(3).

19 Song ZK, Tian ML, Dong YP, Ren CB, Du Y, $\mathrm{Hu}$ J. The C-type lectin IML-10 promotes hemocytic encapsulation by enhancing aggregation of hemocytes in the Asian corn borer Ostrinia furnacalis. Insect Biochem Mol Biol. 2020 Mar;118:103314.

20 Wang P, Zhuo XR, Tang L, Liu XS, Wang YF, Wang GX, et al. WITHDRAWN: C-type lectin interacting with $\beta$-integrin enhances hemocytic encapsulation in the cotton bollworm, Helicoverpa armigera. Insect Biochem Mol Biol. 2017 Jul;86:29-40.
21 Ao J, Ling E, Yu XQ. Drosophila C-type lectins enhance cellular encapsulation. Mol Immunol. 2007 Apr;44(10):2541-8.

22 Cho MY, Lee HS, Lee KM, Homma K, Natori S, Lee BL. Molecular cloning and functional properties of two early-stage encapsulationrelating proteins from the coleopteran insect, Tenebrio molitor larvae. Eur J Biochem. 1999 Jun;262(3):737-44

23 Cho MY, Choi HW, Moon GY, Kim MH, Kwon TH, Homma K, et al. An 86 kDa diapause protein 1-like protein is a component of early-staged encapsulation-relating proteins in coleopteran insect, Tenebrio molitor larvae. Febs Lett. 1999 May;451(3): 303-7.

24 Whitten MM, Tew IF, Lee BL, Ratcliffe NA. A novel role for an insect apolipoprotein (Apolipophorin III) in beta-1,3-glucan pattern recognition and cellular encapsulation reactions. J Immunol. 2004 Feb;172(4):2177-85.

$25 \mathrm{Hu}$ QQ, Wei XH, Li YP, Wang JL, Liu XS. Identification and characterization of a gene involved in the encapsulation response of $\mathrm{He}$ licoverpa armigera haemocytes. Insect $\mathrm{Mol}$ Biol. 2017 Dec;26(6):752-62.

26 Carton Y, Frey F, Stanley DW, Vass E, Nappi AJ. Dexamethasone inhibition of the cellular immune response of Drosophila melanogaster against a parasitoid. J Parasitol. 2002 Apr; 88(2):405-7.

27 Stanley D, Kim Y. Prostaglandins and other eicosanoids in insects: biosynthesis and biological actions. Front Physiol. 2018 Dec;9: 1927.

28 Miltenburger HG, Naser WL, Harvey JP, Huber J, Huger AM. The cellular substrate: a very important requirement for baculovirus in vitro replication. Z Naturforsch, C, Biosci. 1984 Sep-Oct;39(9-10):993-1002.

29 Lehman W, Weilepp M. Establishment of a cell line from hemocytes of Mamestra brassicae L. and its sensitivity to a homologous nuclear polyhedrosis virus (in German). Arhiv Fur Phytopathologie Pflanzenschultz. 1989; 25:387-402.

30 Chisa YA, Imanishi S, Iiyama K, Kawarabata T. Establishment of phagocytic cell lines from larval hemocytes of the beet armyworm, Spodoptera exigua. In Vitro Cell Dev Biol Anim. 2004 Jul-Aug;40(7):183-6. 
31 Belloncik S, Petcharawan O, Couillard M, Charpentier G, Larue B, Guardado H, et al. Development and characterization of a continuous cell line, AFKM-On- $\mathrm{H}$, from hemocytes of the European corn borer Ostrinia nubilalis (Hubner) (Lepidoptera, Pyralidae). In Vitro Cell Dev-An.. 2007 Jul-Aug;43(7):24554.

32 Hu J, Feng X, Yang Z, Chen Z, Zhang W. A continuous cell line, SYSU-OfHe-C, from hemocytes of Ostrinia furnacalis possesses immune ability depending on the presence of larval plasma. Dev Comp Immunol. 2014 Jul; 45(1):10-20.

33 Wang Z-Y, He K-L, Zhang F, Lu X, Babendreier $\mathrm{D}$. Mass rearing and release of Trichogramma for biological control of insect pests of corn in China. Biological Control. 2014 Jan; 68:136-44.

$34 \mathrm{Hu}$ J, Zhu XX, Fu WJ. Passive evasion of encapsulation in Macrocentrus cingulum Brischke (Hymenoptera : Braconidae), a polyembryonic parasitoid of Ostrinia furnacalis Guenee (Lepidoptera : Pyralidae). J Insect Physiol. 2003 Apr;49(4):367-75.

35 Harlow ELD. Antibodies: a laboratory manual. 2nd ed. Cold Spring Harbor, Laboratory Press; 1988.

$36 \mathrm{Hu}$ J, Yu X, Fu W, Zhang W. A Helix pomatia lectin binding protein on the extraembryonic membrane of the polyembryonic wasp Macrocentrus cingulum protects embryos from being encapsulated by hemocytes of host Ostrinia furnaclis. Dev Comp Immunol. 2008; 32(4):356-64.
$37 \mathrm{Hu}$ J, Du Y, Meng M, Dong Y, Peng J. Development of two continuous hemocyte cell sublines in the Asian corn borer Ostrinia furnacalis and the identification of molecular markers for hemocytes. Insect Sci. 2020 Jul: 12854.

38 Lougarre A, Bride JM, Fournier D. Is the insect glutathione S-transferase I gene family intronless?. Insect Mol Biol. 1999 Feb;8(1): 141-3.

39 Zhang Y, Liu Y, Guo X, Li Y, Gao H, Guo X, et al. sHsp22.6, an intronless small heat shock protein gene, is involved in stress defence and development in Apis cerana cerana. Insect Biochem Mol Biol. 2014 Oct;53:1-12.

40 Scherfer C, Qazi MR, Takahashi K, Ueda R, Dushay MS, Theopold U, et al. The toll immune-regulated Drosophila protein Fondue is involved in hemolymph clotting and puparium formation. Dev Biol. 2006 Jul;295(1): 156-63.

41 Goihberg E, Dym O, Tel-Or S, Levin I, Peretz $\mathrm{M}$, Burstein Y. A single proline substitution is critical for the thermostabilization of Clostridium beijerinckii alcohol dehydrogenase. Proteins. 2007 Jan;66(1):196-204.

42 Wang K, Luo H, Tian J, Turunen O, Huang $\mathrm{H}$, Shi $\mathrm{P}$, et al. Thermostability improvement of a Streptomyces Xylanase by introducing proline and glutamic acid residues. Appl Environ Microbiol. 2014 Apr;80(7):2158-65.

43 Nakatogawa S, Oda Y, Kamiya M, Kamijima T, Aizawa T, Clark KD, et al. A novel peptide mediates aggregation and migration of hemocytes from an insect. Curr Biol. 2009 May; 19(9):779-85.
44 Schmidt O, Theopold U, Strand M. Innate immunity and its evasion and suppression by hymenopteran endoparasitoids. Bioessays. 2001 Apr;23(4):344-51.

45 Arai I, Ohta M, Suzuki A, Tanaka S, Yoshizawa Y, Sato R. Immunohistochemical analysis of the role of hemocytin in nodule formation in the larvae of the silkworm, Bombyx mori. J Insect Sci. 2013 Jan;13(1):125.

46 Nardi JB, Pilas B, Bee CM, Zhuang S, Garsha K, Kanost MR. Neuroglian-positive plasmatocytes of Manduca sexta and the initiation of hemocyte attachment to foreign surfaces. Dev Comp Immunol. 2006;30(5):44762.

47 Xu Q, Yu X, Liu J, Zhao H, Wang P, Hu S, et al. Ostrinia furnacalis integrin $\beta 1$ may be involved in polymerization of actin to modulate spreading and encapsulation of plasmatocytes. Dev Comp Immunol. 2012 Jul;37(3-4): 438-45.

48 Levin DM, Breuer LN, Zhuang S, Anderson SA, Nardi JB, Kanost MR. A hemocyte-specific integrin required for hemocytic encapsulation in the tobacco hornworm, Manduca sexta. Insect Biochem Mol Biol. 2005 May;35(5): $369-80$

49 Zhang K, Tan J, Xu M, Su J, Hu R, Chen Y, et al. A novel granulocyte-specific a integrin is essential for cellular immunity in the silkworm Bombyx mori. J Insect Physiol. 2014 Dec;71:61-7. 